\title{
Monitoring Microcirculation: Utility and Barriers - A Point-of-View Review
}

This article was published in the following Dove Press journal:

Vascular Health and Risk Management

\author{
Arnaldo Dubin (1) \\ Vanina Siham Kanoore Edul ${ }^{2}$ \\ Juan Francisco Caminos \\ Eguillor' \\ Gonzalo Ferrara' \\ 'Cátedra de Farmacología Aplicada, \\ Facultad de Ciencias Médicas, \\ Universidad Nacional de La Plata, La \\ Plata, Argentina; ${ }^{2}$ Servicio de Terapia \\ Intensiva, Sanatorio Otamendi, Buenos \\ Aires, Argentina
}

\begin{abstract}
Microcirculation is a particular organ of the cardiovascular system. The goal of this narrative review is a critical reappraisal of the present knowledge of microcirculation monitoring, mainly focused on the videomicroscopic evaluation of sublingual microcirculation in critically ill patients. We discuss the technological developments in handheld videomicroscopy, which have resulted in adequate tools for the bedside monitoring of microcirculation. By means of these techniques, a large body of evidence has been acquired about the role of microcirculation in the pathophysiological mechanisms of shock, especially septic shock. We review the characteristics of sublingual microcirculation in septic shock, which mainly consist in a decrease in the perfused vascular density secondary to a reduction in the proportion of perfused vessels along with a high heterogeneity in perfusion. Even in patients with high cardiac output, red blood cell velocity is decreased. Thus, hyperdynamic flow is absent in the septic microcirculation. We also discuss the dissociation between microcirculation and systemic hemodynamics, particularly after shock resuscitation, and the different behavior among microvascular beds. In addition, we briefly comment the effects of some treatments on microcirculation. Despite the fact that sublingual microcirculation arises as a valuable goal for the resuscitation in critically ill patients, significant barriers remain present for its clinical application. Most of them are related to difficulties in video acquisition and analysis. We comprehensively analyzed these shortcomings. Unfortunately, a simpler approach, such as the central venous minus arterial $\mathrm{PCO}_{2}$ difference, is a misleading surrogate for sublingual microcirculation. As conclusion, the monitoring of sublingual microcirculation is an appealing method for monitoring critically ill patients. Nevertheless, the lack of controlled studies showing benefits in terms of outcome, as well as technical limitations for its clinical implementation, render this technique mainly as a research tool.
\end{abstract}

Keywords: microcirculation, monitoring, sepsis, shock

\section{Introduction}

Microcirculation is the ultimate organ of the cardiovascular system. Microcirculation is a heterogenous and complex network, composed by arterioles, capillaries and venules that connect the arterial and venous system. Its main function resides in satisfying tissue metabolic demands, which is achieved by regulation of organ perfusion and distribution of oxygen flux. Oxygen exchange, carbon dioxide and protons removal, transport of hormones, nutrients, drugs and immune response, among other functions, occur at a microcirculatory level.

The regulation of blood flow takes places at three levels: central, regional and microcirculation. Each level has different determinants and regulatory
Correspondence: Arnaldo Dubin Cátedra de Farmacología Aplicada, Facultad de Ciencias Médicas,

Universidad Nacional de La Plata, La Plata, Argentina

Tel +549II50I0243I

Email arnaldodubin@gmail.com
Vascular Health and Risk Management 2020:16 577-589

DovePress in $\square$ 
mechanisms. ${ }^{1}$ Importantly, blood flow directed to each tissue is carefully determined by local metabolic needs. Under normal conditions, the cardiovascular system is able to meet these demands by restricting oxygen delivery to regions with low metabolic rate while increasing blood flow to regions with high requirements. Redistribution of blood flow among tissues involves extrinsic and intrinsic factors. Extrinsic regulation is accomplished by neural (autonomic) and humoral (hormones) mechanisms. For instances, $\alpha$-adrenergic receptor-mediated vasoconstriction is a main determinant of blood flow redistribution. On the other hand, blood flow within tissues is regulated by intrinsic mechanisms that includes metabolic and vascular control. Vasodilation in response to hypoxia or preservation of blood flow despite changes in perfusion pressure are good examples of these mechanisms, respectively. ${ }^{2}$

Since the main goal of shock resuscitation is the normalization of tissue perfusion and oxygenation, the classic approach based on the correction of blood pressure and cardiac output might fail to correct tissue hypoxia and hypoperfusion. During the resuscitation of shock, two different responses have been described. ${ }^{3}$ The first is characterized by hemodynamic coherence, which implies that the correction of systemic cardiovascular variables results in a parallel improvement in tissue perfusion. Conversely, the other consists in the loss of the hemodynamic coherence. In this case, the normalization of systemic hemodynamics is unable to correct tissue perfusion and oxygenation. Septic shock is the paradigm of this form of dissociation. Even though any type of shock might evolve to this condition, as a consequence of persistent inflammatory response. ${ }^{4}$ Consequently, microcirculatory shock can be defined as a situation in which microvascular flow is insufficient to maintain tissue oxygenation despite of normal(ized) systemic hemodynamics. ${ }^{5}$ Therefore, the monitoring of microcirculation during resuscitation seems necessary to guarantee the restoration of tissue perfusion and oxygenation. This evaluation of the microcirculation might help to detect patients at higher risk of worse outcome, to guide therapy as a target of resuscitation, to monitor the response to therapy, and to unmask persistent shock in apparently well-resuscitated patients. ${ }^{6}$

This point-of-view review will be focused on the direct assessment of sublingual microcirculation, the most suitable window, by means of videomicroscopy.

\section{Development of Clinical Videomicroscopy}

For many years, the clinical approach to the direct intravital observation of microcirculation was restricted to the use of bulky capillary microscopes, which were mainly utilized on the nailfold capillary bed. The introduction of the orthogonal polarization spectral (OPS) imaging device was the first meaningful step for the bedside evaluation of the microcirculation. ${ }^{7}$ The technique consists of a handheld microscope (HVM) that emits polarized light in the wavelength of the spectrum absorption of the hemoglobin. The device has a light guide and a disposable sterile lens at the tip, which can be placed on the tissues (eg, sublingual or intestinal mucosa). Then, the flowing red blood cells (RBC) can be imaged as dark corpuscles flowing through the microcirculation without the need of transillumination or fluorescent dyes. This technique was properly validated by comparisons with the standard fluorescence microscopy. ${ }^{8,9}$ The second generation of HVM was the sidestream dark field (SDF) imaging device. ${ }^{10}$ Compared to OPS, it allows a better capillary contrast and quality visualization. Moreover, SDF has been widely used in experimental and clinical scenarios. The latest generation of HVMs employs Incident Dark Field (IDF) illumination technique with higher resolution optic lens and autofocusing mechanism. ${ }^{11}$ The improved optical system and the lighter weight of IDF imaging allow a field of view, which is three times larger than the previous generation HVM devices, along with better image quality. Consequently, a study showed that up to $30 \%$ more sublingual capillaries could be identified by IDF compared to SDF. ${ }^{11}$ In contrast, an experimental study found that SDF and IDF have a similar capability to identify sublingual vascular densities during both baseline and low flow (shock) states. ${ }^{12}$ Despite this controversy, IDF results in better contrast, sharpness, and image quality. ${ }^{12,13} \mathrm{~A}$ new version of SDF has also demonstrated superior image acquisition when compared to its predecessor. ${ }^{14}$ A comparison between IDF and new SDF system has not been performed yet.

Although there are technical differences among the different HVMs, adequate technologies are nowadays available for the bedside monitoring of microcirculation.

\section{Proper Acquisition of Microcirculatory Videos}

The first step in the monitoring of microcirculation by means of HVM is the acquisition of high-quality videos $^{15}$ (Figure 1). For this purpose, six factors should be carefully taken into account: 


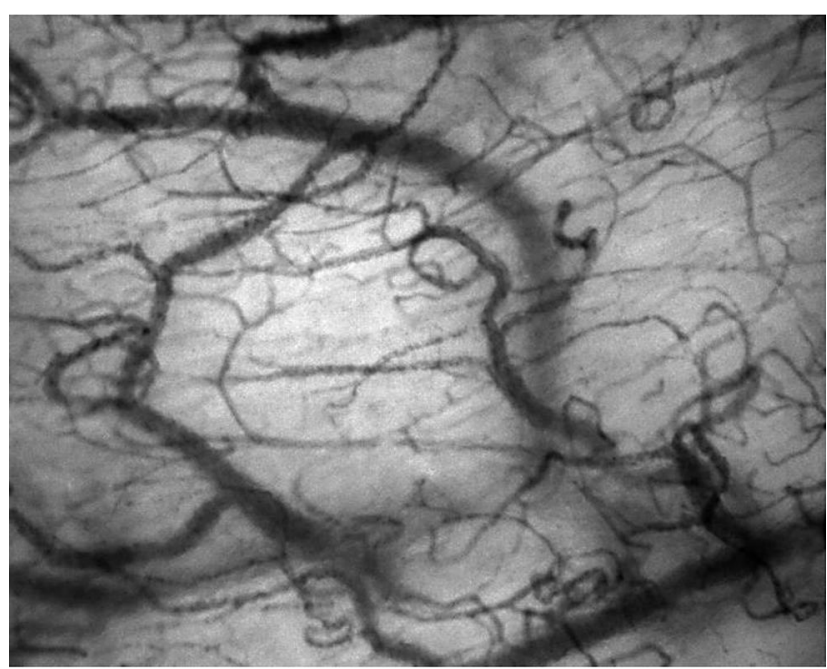

Figure I High-quality image of the sublingual microcirculation obtained by means of incident dark field (IDF) videomicroscopy, with good contrast, adequate focus, and even illumination.

1) Illumination: It should be homogenous in the whole screen, avoiding excessive brightness or darkness. Vessels should be easily identifiable.

2) Duration: It should be enough to allow the characterization of the type of flow in individual vessels, ie, intermittent flow. The ideal duration is 20 seconds.

3) Focus: Images should have adequate sharpness in order to allow RBC identification while vessels border and plasma gaps are visible.

4) Content: the presence of bubbles and saliva may partially hide the view of vessels. In addition, a high proportion of looped vessel structures warns about a nonrepresentative territory.

5) Stability: The overall image movement should be limited to allow an adequate video stabilization that avoids motion blur and permits RBC velocities measurement.

6) Pressure: The application of excessive pressure with consequent compression artifacts is the most common and severe problem in video acquisition. It can result in the diagnosis of inexistent microcirculatory abnormalities. Such artifacts are suspected when flow is uneven, stopped, intermittent, slow, or bidirectional, in large microvessels. Progressive release of the pressure, followed by flow restoration confirms the artifacts. Videos with compression artifacts are not suitable for analysis.

A score of good (0), acceptable (1), or unacceptable (10) should be assigned for the six categories. Videos with a score of 10 in any category are not analyzable because they may produce false results.
The difficulties associated with the video acquisition are not easy to overcome, even for researchers. This point is illustrated by a recent multicenter study, in which the investigators were previously trained in video acquisition. ${ }^{16}$ Yet the authors stated that the proficiency of the study team members was demonstrated before the beginning of the study, $20 \%$ of the time points lacked of images of suitable quality for analysis. Insufficient quality was mainly explained by pressure (40\%) and content artifacts $(30 \%)$.

\section{Analysis of Microcirculatory Videos}

A key issue for the application of videomicroscopy in the clinical scenario is the proper quantification of the microvascular abnormalities. An objective and quantitative assessment is desirable in order to identify abnormalities and to monitor the response to therapeutic modalities. The evaluation should be focused on small vessels $(<20 \mu \mathrm{m})$, albeit the patency of flow in larger microvessels (venules and arterioles) is required to rule out compression artifacts. The first approach to the clinical analysis of sublingual microcirculatory videos was the identification of the number of microvessels and the characteristics of blood flow, which was performed by eye. ${ }^{17}$ In this analysis, a grid consisting of three equidistant horizontal and three equidistant vertical lines are drawn in the screen. Then, the total vascular density (TVD) is estimated as the number of vessels crossing these lines divided by the total length of the grid. Additionally, the proportion of perfused vessels (PPV) is calculated as the ratio between those with continuous flow - normal or sluggish - and the total number of vessels. Consequently, the perfused vascular density (PVD) is derived as the product of the TVD by the PPV. On the other hand, the features of microvascular perfusion have been evaluated as the microvascular flow index (MFI). For this purpose, the image is divided into four quadrants and the predominant type of flow (absent $=0$, intermittent $=1$, sluggish $=2$, and normal $=3$ ) is assessed in each quadrant. Then, the MFI is computed as the average of the predominant flow in each of the four quadrants. ${ }^{18}$ Another approach to the MFI determination is to average the type of flow of each individual vessel. ${ }^{19}$ Yet this procedure is more cumbersome, the resultant MFI shows a better correlation with the actual red RBC velocity.

Microcirculatory heterogeneity is usually reported as the heterogeneity flow index, which is calculated as the difference between highest MFI minus the lowest site MFI 
divided by the mean MFI. ${ }^{20}$ Another assessment of heterogeneity is the coefficient of variation of RBC velocity. ${ }^{21}$

The first consensus conference about the evaluation of microcirculation stated that the ideal analysis report should include measurements of vessel density, perfusion indices, and heterogeneity. ${ }^{22}$ Measurements of density (TVD and PVD) and perfusion (MFI, PPV, and RBC velocity) refer to the diffusional and convective components of the microvascular oxygen transport, respectively. The most comprehensive variable in the microcirculatory evaluation is PVD because it takes into account the diffusional (density) and the convective (presence of continuous flow) determinants of microcirculatory oxygenation.

The simplest approach to TVD is to count the number of microvessels present in the screen or crossing a gridline. ${ }^{17}$ An exact determination of the TVD can be accomplished by means of software analysis. Until now, the only validated software for the microcirculatory analysis is AVA 3.2. ${ }^{23}$ Actually, it does not allow an automatic analysis but a software-assisted analysis. Despite the fact that it is time-consuming, it gives a precise determination of TVD as length by surface $\left(\mathrm{mm} / \mathrm{mm}^{2}\right)$. A manual correction of background defects, which are misinterpreted as vessels, is possible. Besides, microvessels unrecognized by the software can be manually drawn. Then, the PVD can be calculated as the TVD multiplied by the PPV. In addition, $\mathrm{RBC}$ can be measured in individual microvessels by the use of space-time diagrams. This procedure is cumbersome and requires interactions with the operator. AVA software has been properly validated and should be considered the gold standard for comparisons with other methods. ${ }^{23}$

Although AVA software assisted analysis gives an exact assessment of microcirculation, it is timeconsuming and requires off-line analysis performed by trained investigators. To target the microcirculation as an end-point for resuscitation, an automated real-time analysis of videos is required. Recently, MicroTools, a new software, which enables automated quantification of capillary density and red blood cell velocity in HVM has been developed. ${ }^{24}$ It was compared and validated against AVA 3.2 software. Beyond the precise determination of TVD and PVD, it measures RBC velocity in every microvessel. In this way, it might give a complete depiction of microvascular perfusion. Even though this software constitutes a milestone development in microvascular analysis, we have some concerns about the published results. In the validation study, 53 images taken in experimental septic shock and controls pigs were analyzed by the two methods. Although good correlations were observed for TVD, PVD and PPV between both methods, there was a considerable lack of agreement with the results obtained with AVA 3.2 software. Accordingly, 95\% limits of agreement between both methods were wide: 13.2 and $12.3 \mathrm{~mm} / \mathrm{mm}^{2}$ for TVD and PVD, respectively; 0.34 for the PPV, and $329 \mu \mathrm{m} / \mathrm{s}$ for RBC velocity. As stated by Bland and Altman, these values are not clinically acceptable and cannot be considered interchangeable. ${ }^{25}$ In addition, values of $\mathrm{RBC}$ velocity were quite lower than those previously reported in clinical and experimental research. ${ }^{23,26-28}$ In 53 HVM image sequences, 2116 vessels were detected by the algorithm, 1922 of which were classified as capillaries. These findings imply that there was an average of 36 capillaries per video. These figures are quite lower than the usual number of about 200 per video identified by AVA 3.2 software in IDF images, in both sheep and humans (unpublished data). A potential advantage of the automatic software is the measurement of $\mathrm{RBC}$ velocity in every capillary. According to the previous discussion, however, MicroTools measured velocity in only 36 vessels per video, which is higher than what it is usually performed with AVA software (20/video), but not extremely different. Therefore, we believe that further validation of this software is required before considering it as interchangeable with the gold standard.

Another approach to the quantification of the microvascular disorder is real-time point-of-care (POC) assessment, which means that a rapid evaluation is performed by eye, during or immediately after the video acquisition. The aforementioned task force stated that POC evaluation at the bedside shows good agreement with off-line analysis. In our opinion, however, the supporting evidence is weak. In a study comparing POC and offline determination of MFI, 95\% limits of agreement for the simultaneous measurements were unacceptable wide. ${ }^{29}$ The lack of interchangeability was further confirmed by different studies. ${ }^{18,30,31}$ Other recent studies claim the advantages of POC analysis but they have conceptual mistakes, such as considering that $25 \%$ is the limit of normality for unperfused vessels, which actually is a severe alteration. Another study used an MFI greater than 2.5, a PCD greater than $10.3 \mathrm{~mm} / \mathrm{mm}^{2}$, and a PPV greater than 0.64 as cutoff points to define the microcirculation as good. ${ }^{32}$ The main weakness of POC assessment is that considers as normal what actually are moderate-to-severe alterations. Although these approaches might identify gross abnormalities, they 
probably fail to detect minor or subtle alterations, which are more commonly present in most of the critically ill patients. They could also fail to recognize changes from basal measurements. Accordingly, a recent study showed that a POC evaluation failed to notice microcirculatory abnormalities, which were identified by the off-line analysis. ${ }^{33}$ Therefore, its usefulness is quite limited.

\section{Microvascular Alterations in Critical Conditions}

To better characterize microvascular abnormalities, a consensus on the assessment of sublingual microcirculation in critically ill patients presented a classification that defines the four most common microcirculatory alterations previously described in various clinical scenarios. ${ }^{6}$ This classification comprises:

Type 1: complete stagnated capillaries (circulatory arrest and excessive use of vasopressors).

Type 2: reduction in number of capillaries with continuous flow (hemodilution).

Type 3: stopped flow vessels next to vessels with flowing cells (sepsis, hemorrhage, and hemodilution).

Type 4: hyperdynamic capillary flow (hemodilution, sepsis).

We have some concerns about some statements of this classification. Obviously, cardiac arrest expectedly results in complete stopped microvessels. Even though excessive use of vasopressors might decrease perfused capillary density, ${ }^{34}$ the complete microvascular stagnation has only been reported as an anecdotal finding. ${ }^{35}$ In addition, the decrease in the proportion of capillaries with continuous flow is almost a ubiquitous characteristic in any clinical situation associated with microvascular disorders (sepsis, hemorrhage, cardiac failure, post-operatory, etc.). The type 3 , which is equivalent to heterogeneity, has also been described in many clinical and experimental situations. $^{21,26}$ Finally, hyperdynamic microcirculation seems to be more a theoretical speculation than actual condition. As a matter of fact, RBC velocity is low in either septic shock or hemodilution. ${ }^{36,37}$

In our opinion, the proposed classification could not contribute to a better differentiation of clinical entities. As the consensus pointed out, these types of alterations can occur at the same time, as an expression of different pathogenic mechanisms can occur, especially in complex disease states such as sepsis. Actually, the overlap among the different types of alterations develop not only in sepsis but also in other pathophysiologic conditions such as hemorrhagic shock, reperfusion injury and hemodilution.

Furthermore, another relevant microcirculatory component is the glycocalyx, which can be also assessed by videomicroscopic techniques. This review, however, is focused on the variables discussed in the recent consensus. $^{6}$

\section{Sublingual Microcirculation in Sepsis Characteristics of the Microcirculation in Septic Shock}

Microcirculation can be affected in septic shock by several mechanisms. These include endothelial dysfunction, glycocalyx degradation, capillary leak, loss of vascular reactivity and autoregulation, and microthrombosis. ${ }^{38}$ In experimental studies, septic microcirculation is characterized by increased number of unperfused vessels, reduced PCD, and increased heterogeneity. ${ }^{39-41}$ Consequently, a functional shunting of oxygen from arterioles to venules might develop, decreasing oxygen extraction ratio $\left(\mathrm{O}_{2}\right.$ ER). ${ }^{42}$

A landmark study showed the presence of severe abnormalities of sublingual microcirculation in septic patients. ${ }^{17}$ The alterations consist in: 1) decrease in vascular density; 2) reduction in PPV resulting from an increased number of vessels with stopped or intermittent flow; and 3) increase in heterogeneity. Further studies demonstrated that these disorders are more severe in nonsurvivors than in survivors, ${ }^{21,29,43}$ improve over time only in survivors, ${ }^{44}$ and are independent predictors of mortality in septic patients. ${ }^{45}$ Therefore, sublingual microcirculation has relevant prognostic implications in sepsis.

We performed the first quantitative evaluation of sublingual microcirculation by means of a software-assisted analysis, in normal volunteers and patients with septic shock. ${ }^{21}$ The study found that septic microcirculation is characterized by 1) decrease in PCD that entirely results from the reduction in the PPV, given that the TVD is preserved. 2) Increase in heterogeneity. 3) Decrease in RBC velocity (Figures 2 and 3). While PVD and heterogeneity were more affected in nonsurvivors than in survivors, RBC velocity was similar in both. Thus, the compromise of diffusional oxygen availability variables, such as PCD and heterogeneity, are more associated to mortality than a pure convective parameter such as RBC velocity. Actually, the most striking difference between healthy volunteers and patients with septic shock, as well 

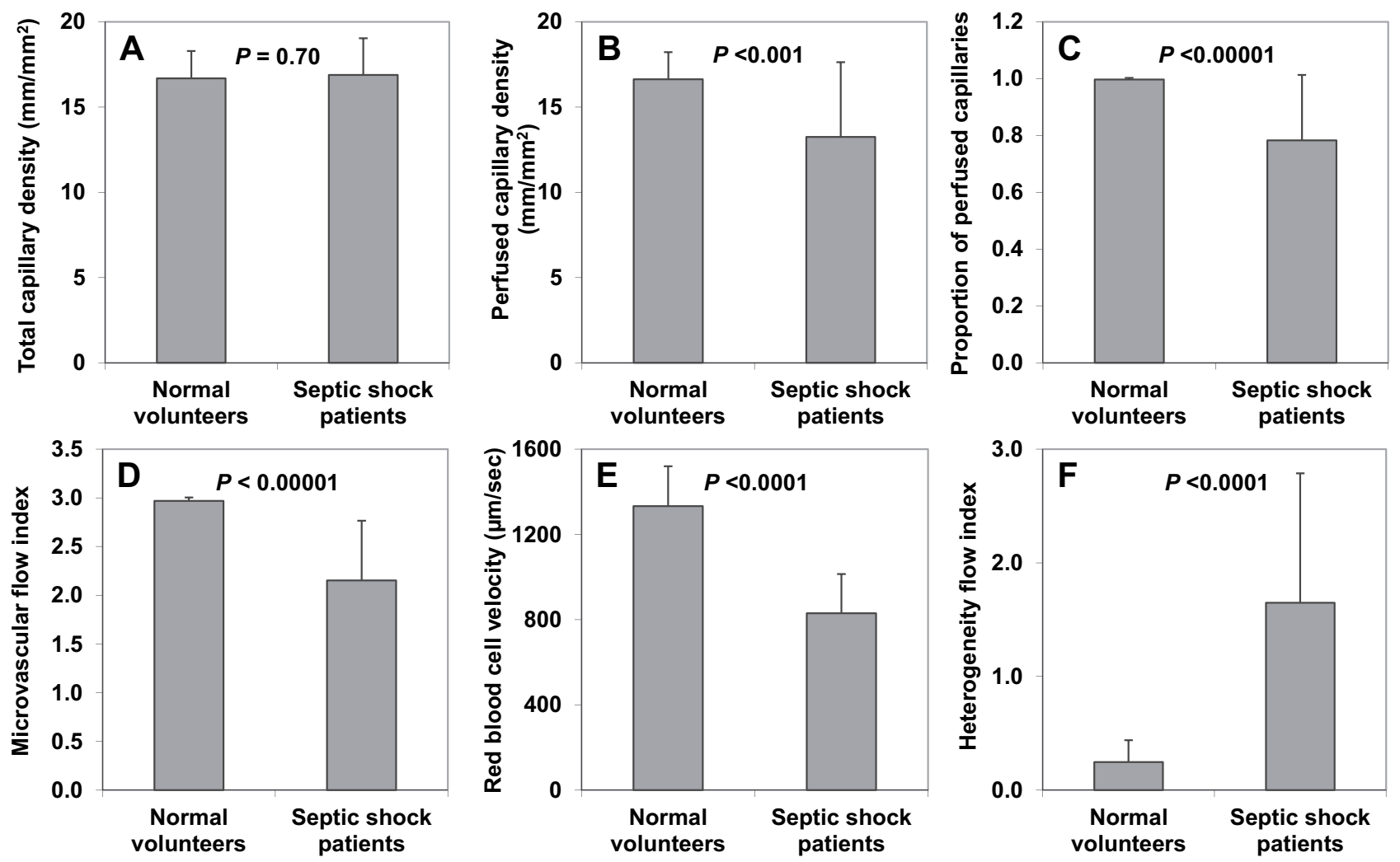

Figure 2 Microcirculatory variables in healthy volunteers and patients with septic shock. (A) Total capillary density. (B) Perfused capillary density. (C) Proportion of perfused capillaries. (D) Capillary microvascular flow index. (E) Capillary red blood cell velocity. (F) Capillary heterogeneity flow index. Reproduced with permission from Edul VS, Enrico C, Laviolle B, Vazquez AR, Ince C, Dubin A. Quantitative assessment of the microcirculation in healthy volunteers and in patients with septic shock. Crit Care Med. 20I2;40(5):I443-1448. ${ }^{21}$

as between survivors and nonsurvivors, was in heterogeneity flow index. In another study, such difference in the heterogeneity flow index was not found. ${ }^{16}$ Yet, there was a nonsignificant trend to increased heterogeneity in nonsurvivors, which was about $50 \%$ higher than in survivors. Discrepancies between the studies might be related to the approach for the characterization of microvascular flow. In the quoted study, MFI and heterogeneity were determined by quadrant analysis, instead of vessel by vessels, as we did. $^{21}$

During the early resuscitation of septic shock, microcirculation can be correlated with systemic cardiovascular variables. $^{29,46}$ Thereafter, the microcirculation is frequently dissociated from systemic hemodynamics. ${ }^{17,21,44}$ Consequently, microvascular perfusion cannot be predicted by systemic hemodynamics. In nonsurvivors from septic shock, however, severe microvascular abnormalities go along with lactic acidosis, tachycardia, and high doses of norepinephrine. ${ }^{21,43}$

The presence of hyperdynamic flow in the septic microcirculation is controversial. The increase in $\mathrm{RBC}$ velocity might decrease tissue $\mathrm{O}_{2} \mathrm{ER}$. A mathematical model stated that a short RBC capillary transit time might not allow the complete unload of $\mathrm{O}_{2}{ }^{47}$ The existence of hyperdynamic flow has been supposed, but never clearly shown. An experimental study described an increased proportion of fast-to normal-flow capillaries but the number capillaries with high flow were unchanged. Consequently, this finding was explained by the reduction in the number of capillaries with normal flow. ${ }^{40}$ In contrast, RBC velocities were low in other experimental studies. $^{27,48,49}$

We studied the RBC velocity by means of space-time diagrams, in healthy volunteers and patients with septic shock. Surprisingly, RBC velocities in sublingual capillaries were quite similar in patients with either normodynamic or hyperdynamic septic shock. In both situations, there was a shift of the histogram of RBC velocity to lower values, compared to healthy volunteers ${ }^{36}$ (Figure 4). Even after a fluid challenge that improved cardiac index from $2.6 \pm 0.5$ to $3.3 \pm 1.0 \mathrm{~L} / \mathrm{min} / \mathrm{m}^{2}$, RBC velocity increased from $912 \pm 270$ to $1064 \pm 200 \mu \mathrm{m} / \mathrm{s}$ but remained 

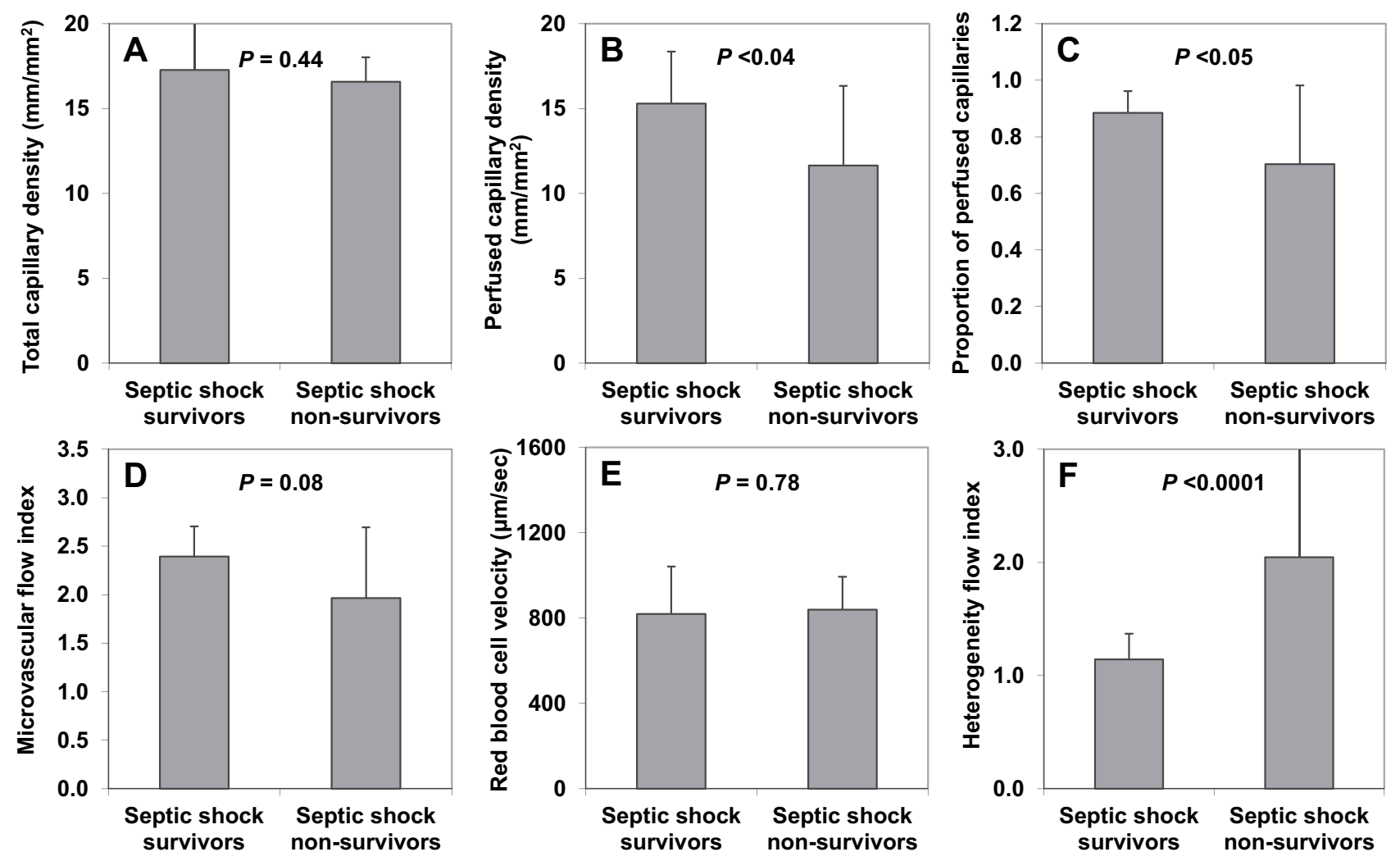

Figure 3 Microcirculatory variables in survivors and nonsurvivors with septic shock. (A) Total capillary density. (B) Perfused capillary density. (C) Proportion of perfused capillaries. (D) Capillary microvascular flow index. (E) Capillary red blood cell velocity. (F) Capillary heterogeneity flow index. Reproduced with permission from Edul VS, Enrico C, Laviolle B, Vazquez AR, Ince C, Dubin A. Quantitative assessment of the microcirculation in healthy volunteers and in patients with septic shock. Crit Care Med. 2012;40(5):|443-1448. ${ }^{21}$

lower than $1331 \pm 90 \mu \mathrm{m} / \mathrm{s}$, which are the values found in healthy volunteers. ${ }^{50}$

In contrast to septic shock, hyperdynamic capillaries were found during cardiac surgery and in clinically stable cirrhotic patients, especially in those with high MELD scores. ${ }^{51,52}$ Both conditions can be associated with distributive alterations in cardiac output.

\section{Heterogeneity Among Different Microvascular Beds}

Beyond the presence of microvascular heterogeneity within the sublingual microcirculation, a further question is if this microvascular bed reflects other territories, such as the gut mucosa. Otherwise, intestinal hypoperfusion might develop despite the preservation of sublingual microcirculation. Villi hypoperfusion has been associated with barrier dysfunction, with subsequent translocation of bacteria and their products to the systemic circulation, which is putative mechanism of multiple organ failure. ${ }^{53}$ Sublingual and gut microcirculation behaved differently in some experimental situations. In a model of sheep endotoxemia, ileal villi microcirculation persisted hypoperfused albeit the normalization of sublingual perfusion. ${ }^{41}$ In another study, fluid resuscitation improved both territories, but villi PVD remained hypoperfused. ${ }^{54}$ In contrast, in a model of cholangitis, abnormalities were similar in both microvascular beds. ${ }^{27}$ The findings of the latter study might be explained by a reduction in the PPV to about 0.30 , which is an extreme and uncommon alteration. Accordingly, a more homogeneous disorder might have affected both territories. In patients with abdominal sepsis, sublingual and intestinal stoma MFIs had a poor correlation during the first postoperative day. ${ }^{55}$ We also noticed in patients with abdominal sepsis, a similar dissociation between sublingual and intestinal microcirculation at baseline and after a fluid challenge. ${ }^{50}$ Intravascular volume expansion improved the sublingual microcirculation but the intestinal villi persisted ischemic. Furthermore, the intestinal microvascular indices were more severely compromised in nonsurvivors than in survivors, but sublingual variables were similar. Nonetheless, these results do not 
A

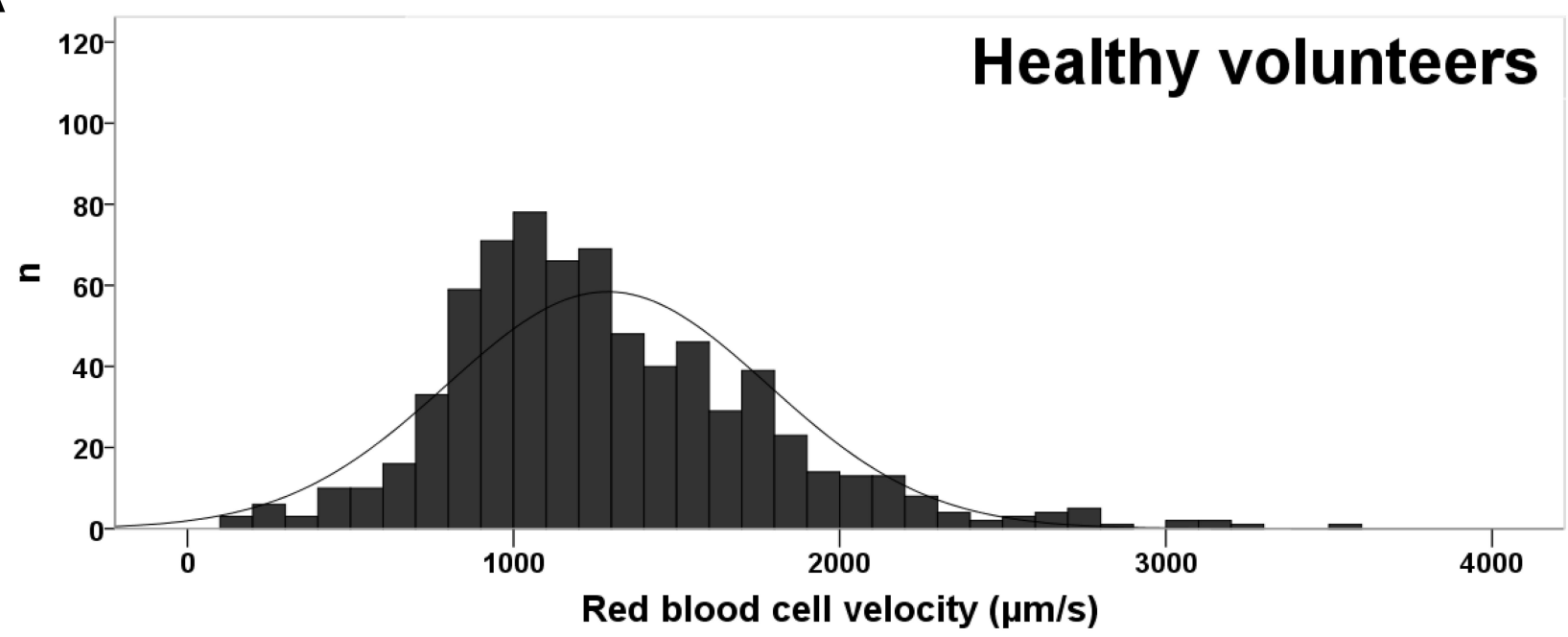

B

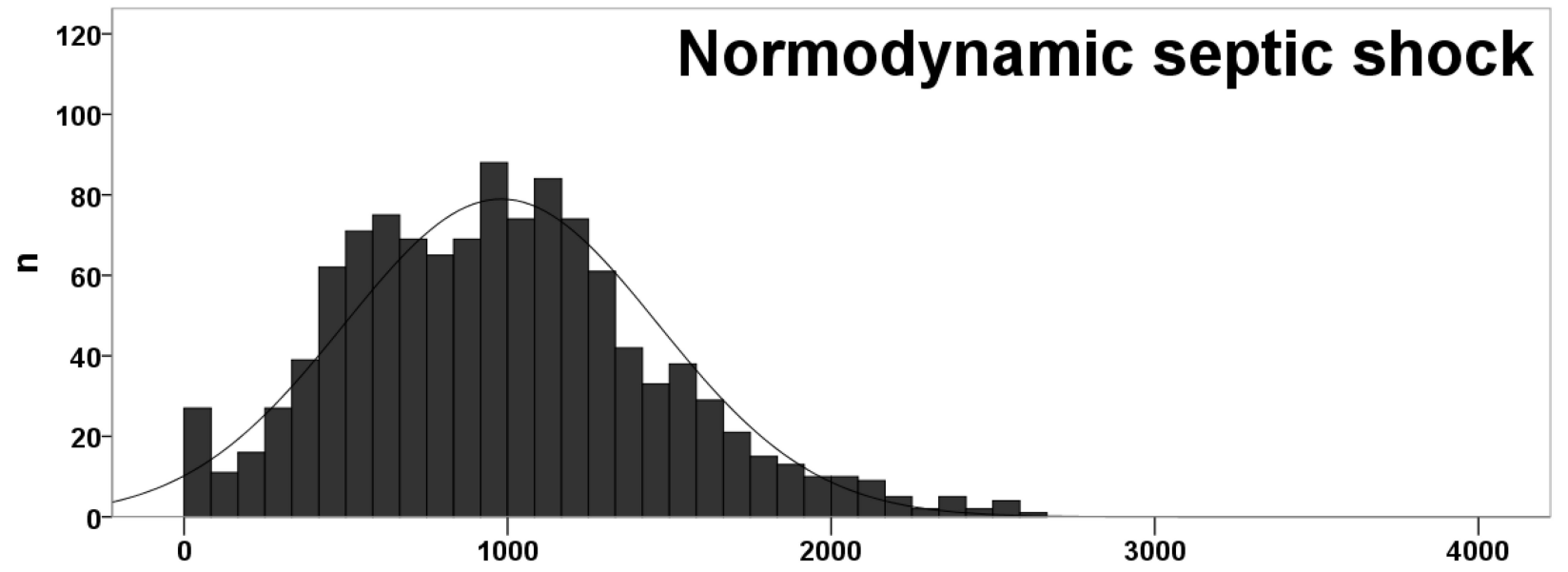

Red blood cell velocity $(\mu \mathrm{m} / \mathrm{s})$

C

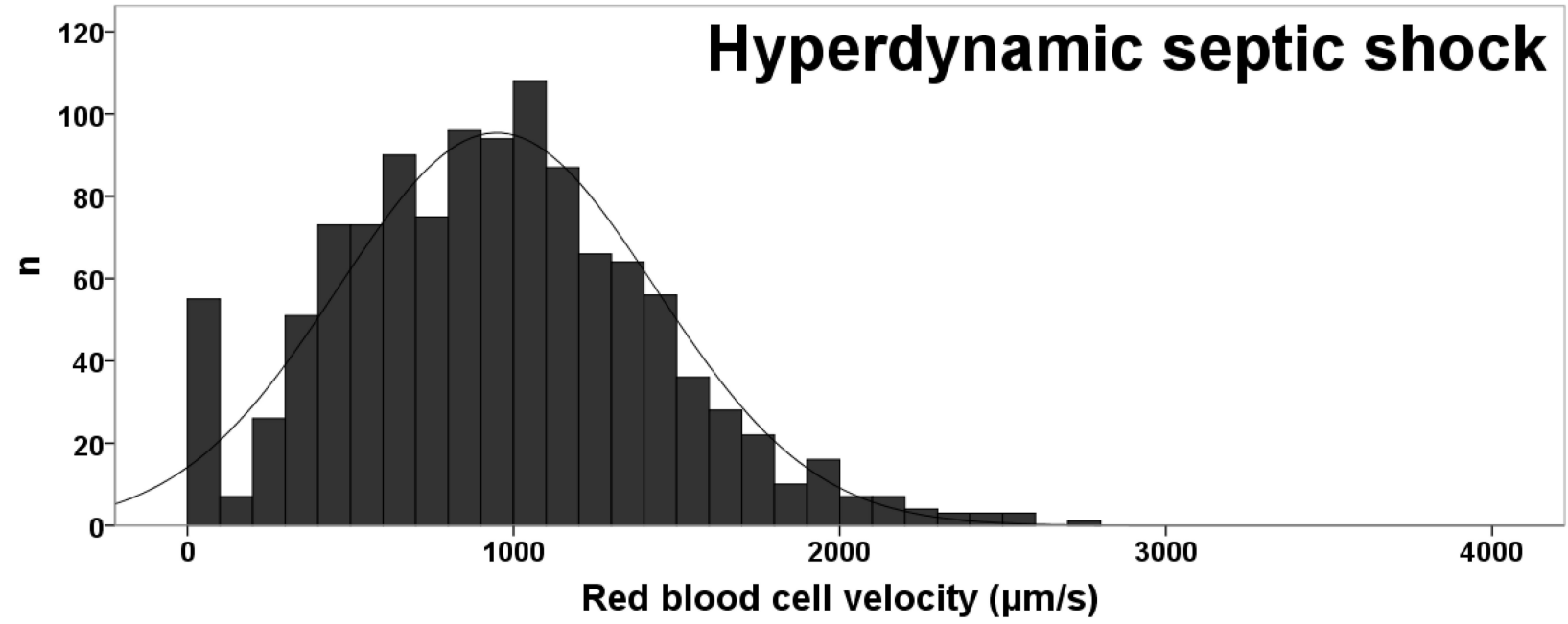

Figure 4 Histograms of capillary red blood cell (RBC) velocities. (A) Healthy volunteers. (B) Patients with normodynamic septic shock. (C) Patients with hyperdynamic septic shock. Reproduced with permission of the Americal Thoracic Society. Copyright (C 2016 American Thoracic Society. All rights reserved. Edul VS, Ince C, Vazquez AR, et al. Similar Microcirculatory Alterations in Patients with Normodynamic and Hyperdynamic Septic Shock. Ann Am Thorac Soc. 20I6;13(2):240-247). ${ }^{36}$ Annals of the American Thoracic Society is an official journal of the American Thoracic Society. 
challenge the established value of sublingual microcirculation as a prognostic index in septic patients, but simply reflect that, in these surgical patients, the local ischemia in the villi is probably more relevant than the state of perfusion in other vascular beds. Accordingly, isolated villi ischemia might affect the outcome in the absence of microvascular disorders in other territories because of the putative role of that vascular bed in the development of multiorgan failure. ${ }^{53}$ Nevertheless, the most sensitive microvascular bed seems the kidney. In experimental models of hemorrhagic and septic shock, renal peritubular capillaries are more severely disrupted than sublingual and villi microcirculation. ${ }^{56,57}$

\section{Microcirculatory Response to Resuscitation}

Different therapeutic modalities might correct microcirculatory alterations. Since a detailed review of them exceeds the scope of this review, we only summarize the effects of routinely used treatments such as fluids, vasopressors and inotropes. In spite of these results, a recent sub-analysis of a large multicenter randomized controlled study showed that the characteristics of sublingual microcirculation were similar in the three arms of early resuscitation of septic shock, albeit the use of fluids, vasopressors and inotropes was different. ${ }^{16}$ Given that blood pressure, lactate and measures of outcome did not differ among the groups, an explanation for these results might be that the final effects of the resuscitation strategies on systemic hemodynamics and microcirculation had also been similar. Unfortunately, well-designed controlled trials aimed at improving microcirculation are lacking.

\section{Fluids}

Fluids are the first approach in the resuscitation of septic shock. The effects of fluids on the microcirculation depend on several factors. ${ }^{58}$ Fluids can improve convective microvascular flow because of the increases in cardiac output and blood pressure. Nevertheless, an excess in intravascular volume expansion can reduce diffusional microvascular oxygen transport because of the development of tissue edema. This might decrease the PVD and the area for gas exchange, and increase the diffusional distance. Additionally, a lower viscosity might reduce capillary flow and hematocrit. ${ }^{59}$

Regarding the type of fluid, many experimental studies demonstrated positive effects of starches on the microcirculation. ${ }^{60,61}$ In addition, a small-randomized controlled study showed better effects than saline solution on sublingual microcirculation. ${ }^{62}$ The untoward effects of starches, however, preclude their utilization in critically ill patients. ${ }^{63}$

Another important issue is the selection of patients who might benefit from volume administration. The timing of solution administration is a key factor. In sepsis, the early administration $(<24 \mathrm{~h})$ improve sublingual microcirculation but the delayed indication $(>48 \mathrm{~h})$ is ineffective. ${ }^{64}$ Patients with septic shock and fluid responsiveness improve the sublingual microcirculation in response to fluid challenge. These changes correlated with variations in cardiac output. ${ }^{65}$

The effects of fluid resuscitation also depend on the basal state of microcirculation. In patients with an MFI $<2.6$, there were improvements in microcirculation and compromised organ perfusion. ${ }^{66}$ In contrast, no benefits arose with $\mathrm{MFI} \geq 2.6$. We showed that the effects of fluid challenge on sublingual microcirculation depend on both the microcirculatory status at baseline and the amount of the increase in cardiac output. ${ }^{50}$ Indeed, fluid bolus would cause higher improvement in microcirculation when cardiac output markedly increases and in patients with a basal microcirculation severely compromised. Accordingly, the evaluation of microcirculation, before the intravascular volume expansion, might predict a useful intervention. ${ }^{58}$

\section{Vasopressors}

The aim of vasopressors is to reach a perfusion pressure above the lower limit of autoregulation that allows tissue perfusion, while avoiding excessive vasoconstriction. In patients with septic shock, increases in mean arterial pressure (MAP) from 60 to $90 \mathrm{~mm} \mathrm{Hg}$ by means of norepinephrine improved systemic oxygen delivery and skin perfusion increased without detrimental effects on the sublingual microcirculation. The authors concluded systemic hemodynamics and oxygen transport could be improved without deterioration of the previous microcirculatory alterations. ${ }^{67}$ A more detailed analysis shows that when MAP increased from 70 to $90 \mathrm{~mm} \mathrm{Hg}$, there were falls in the MFI, the PPV and the PCD of about $10 \%$. In patients with septic shock, we showed that the increase in MAP from 65 to 75 , and then to $85 \mathrm{~mm} \mathrm{Hg}$ was associated with a linear trend to a reduced PCD. ${ }^{34}$ The key result, however, was that the highly variable effects were strongly dependent on the basal state of the microcirculation. If PCD was preserved at a MAP of $65 \mathrm{~mm} \mathrm{Hg}$, elevations in MAP decreased the PCD, likely because of excessive vasoconstriction. On the other hand, the increase in MAP, in patients with an altered basal PCD, improved the 
A

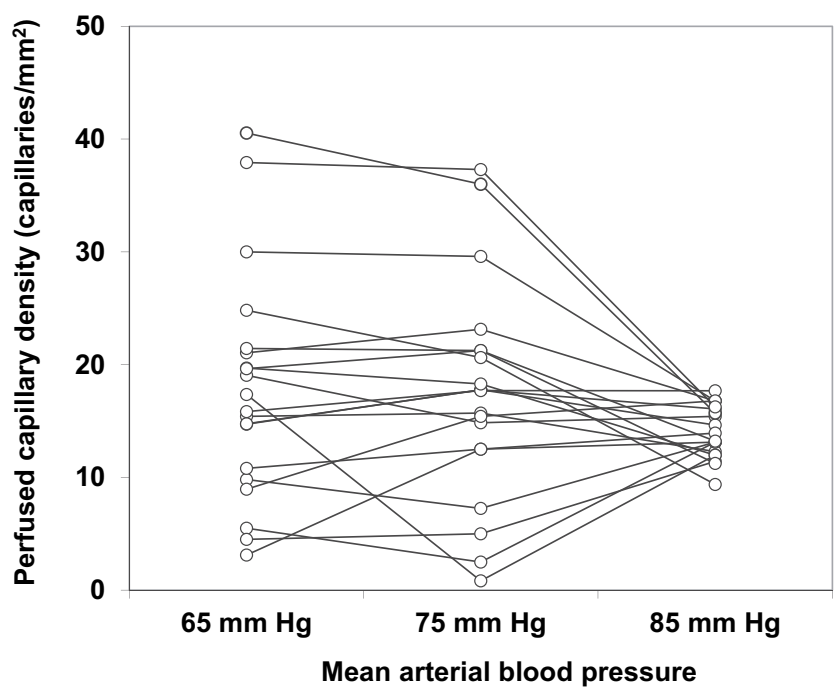

B

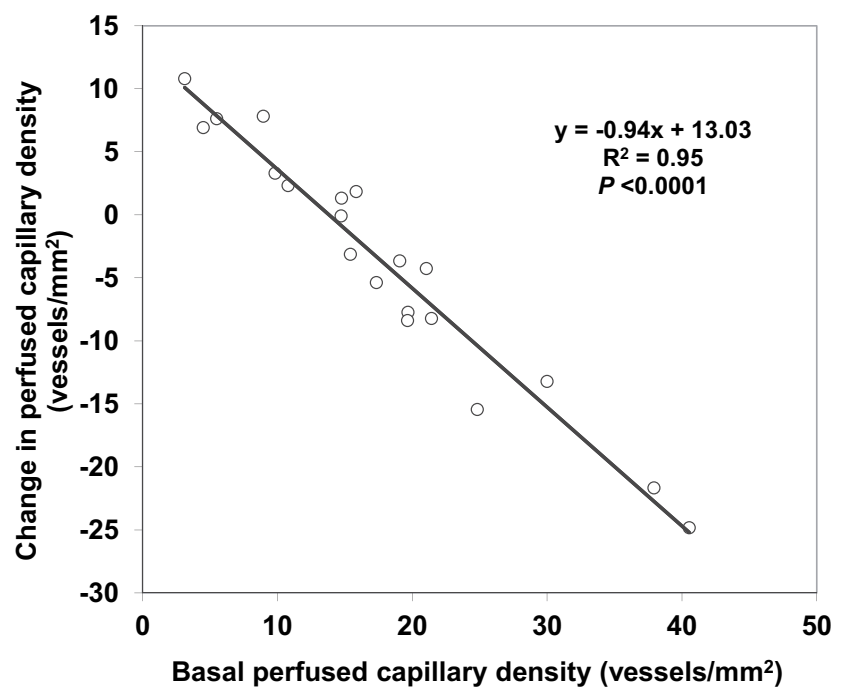

Figure 5 (A) Sublingual perfused capillary density at 65, 75, and $85 \mathrm{~mm} \mathrm{Hg}$ of mean arterial blood pressure. (B) Correlation between basal sublingual perfused capillary density (at $65 \mathrm{~mm} \mathrm{Hg}$ of mean arterial blood pressure) and the change in sublingual perfused capillary density at increasing values of mean arterial blood pressure. Reprinted with permission from Dubin A, Pozo MO, Casabella CA, et al. Increasing arterial blood pressure with norepinephrine does not improve microcirculatory blood flow: a prospective study. Crit Care. 2009;13(3):R92. Copyright (C) 2009 Dubin et al. ${ }^{34}$

microcirculation (Figure 5). The correlation between the microcirculatory variables at baseline and their changes after the MAP increase was confirmed in another study. ${ }^{68}$ The clinical implication is that the optimal MAP might be selected according to microcirculatory status.

\section{Inotropes}

The increase in cardiac output elicited by inotropes might go together with increases in microvascular perfusion. In spite of this, an observational study found that an infusion of $5 \mu \mathrm{g} / \mathrm{kg} / \mathrm{min}$ of dobutamine improves the PPV from $58 \%$ to $75 \%$, regardless of the changes in cardiac output or MAP. ${ }^{69}$ In contrast, we found that increasing doses of dobutamine do not increase microvascular in patients with septic shock. ${ }^{70}$ These conflicting responses to dobutamine might be explained again to the different microvascular states at baseline, in each study. In our study, patients with more severe alterations (PCD $\leq 12 \mathrm{~mm} / \mathrm{mm}^{2}$ ) improved their microcirculatory, similarly to the aforementioned study. ${ }^{69}$ Accordingly, in this subgroup of patients, the PPV increased from 0.57 to 0.72 . Therefore, in the presence of severe derangements in sublingual perfusion, dobutamine has beneficial effects on sublingual microcirculation. Besides, a small study showed that dobutamine has a nonsignificant trend to improve sublingual PPV, from 0.75 to $0.79(p=0.09)$, albeit worsens tissue muscular oxygenation and hepatic perfusion. ${ }^{71}$

\section{Is Venoarterial $\mathrm{PCO}_{2}$ a Surrogate for Sublingual Microcirculation?}

Some years ago, an observational study, in patients with septic shock, showed that central venous minus arterial $\mathrm{PCO}_{2}\left(\mathrm{P}_{\mathrm{cv}-\mathrm{a}} \mathrm{CO}_{2}\right)$ correlated with sublingual microcirculation, but not with cardiac output. ${ }^{72}$ The authors suggested that $\mathrm{P}_{\mathrm{cv}-\mathrm{a}} \mathrm{CO}_{2}$ might reflect microvascular perfusion. Even though the supporting evidence is weak, there is a widespread concept that $\mathrm{P}_{\mathrm{cv}-\mathrm{a}} \mathrm{CO}_{2}$ can be used as a surrogate for microcirculation assessment. ${ }^{73}$ These conclusions, however, overlook basic physiological principles.

As clearly shown by a systematic review and large studies in septic patients, $\mathrm{P}_{\mathrm{cv}-\mathrm{a}} \mathrm{CO}_{2}$ highly depends on cardiac output. ${ }^{74,75} \mathrm{P}_{\mathrm{cv}-\mathrm{a}} \mathrm{CO}_{2}$, however, is also determined by $\mathrm{CO}_{2}$ production and $\mathrm{CO}_{2}$ dissociation curve. These factors explain why the relationship between cardiac output and $\mathrm{P}_{\mathrm{cv}-\mathrm{a}} \mathrm{CO}_{2}$ is not straightforward. When venous $\mathrm{O}_{2}$ saturation increases by improved flow, changes in $\mathrm{CO}_{2}$ pressure and content can differ because of Haldane effect. For example, dobutamine-induced increases in cardiac output do not decrease $\mathrm{P}_{\mathrm{cv}-\mathrm{a}} \mathrm{CO}_{2}$ as a probable result of simultaneous increases in venous oxygen saturation. ${ }^{76}$ Besides, for a same $\mathrm{C}_{\mathrm{v}-\mathrm{a}} \mathrm{CO}_{2}$, metabolic acidosis can also increase venoarterial $\mathrm{PCO}_{2}$. In the absence of hemodynamic changes, a decrease of only $3 \mathrm{mEq} / 1$ in base excess increases venoarterial $\mathrm{PCO}_{2}$ by $50 \%{ }^{77}$ Anemia also 
affects $\mathrm{CO}_{2}$ transport. Hemodilution induces opposite effects on $\mathrm{CO}_{2}$ pressure and content difference. The former increases and the latter decreases. ${ }^{78}$

Unlike $\mathrm{P}_{\mathrm{cv-a}} \mathrm{CO}_{2}$, tissue-arterial $\mathrm{PCO}_{2}$ actually reflects microcirculatory perfusion. ${ }^{41,79}$ Experimental and clinical studies support this point of view. In endotoxic shock, venoarterial, and tissue minus arterial $\mathrm{P}_{\mathrm{cv}-\mathrm{a}} \mathrm{CO}_{2}$ increase as an expression of low cardiac output, mesenteric flow, and villi microcirculatory perfusion. ${ }^{41}$ Fluid resuscitation normalizes cardiac output and mesenteric flow but fails to restore villi perfusion. Accordingly, systemic and mesenteric venoarterial $\mathrm{PCO}_{2}$ return to normal but mucosal minus arterial $\mathrm{PCO}_{2}$ remains elevated as an expression of microvascular villi hypoperfusion. In septic patients, sublingual microcirculatory alterations are similar regardless the normo- or hyperdynamic pattern. ${ }^{36}$ In contrast, $\mathrm{P}_{\mathrm{cv}-\mathrm{a}}$ $\mathrm{CO}_{2}$ is higher in normodynamic than in hyperdynamic septic shock.

Concisely, $\mathrm{P}_{\mathrm{cv}-\mathrm{a}} \mathrm{CO}_{2}$ primarily reflects cardiac output but also depends on factors that modify the dissociation of $\mathrm{CO}_{2}$ from hemoglobin and $\mathrm{CO}_{2}$ production. Its use as a surrogate for microcirculatory perfusion is misleading.

\section{Conclusions}

Despite the fact that the monitoring of sublingual microcirculation seems an attractive variable for the monitoring of critically ill patients as a prognostic tool and an aim for the resuscitation, significant barriers remain present. Now, these are mainly related to video acquisition and analysis. Hopefully, improvements in automatic analysis will contribute to overcome these limitations. Then, optimal cutoffs of microvascular variables should be established as goals of treatment. Finally, randomized controlled trials, aimed at showing that a microcirculation-target resuscitation improves the outcome, could give enough evidence to support its clinical implementation. In the meantime, the monitoring of sublingual microcirculation mainly remains as a research tool.

\section{Funding}

This research did not receive any specific grant from funding agencies in the public, commercial, or not-forprofit sectors.

\section{Disclosure}

The authors report no conflicts of interest for this work.

\section{References}

1. Morisaki H, Sibbald W. Tissue oxygen delivery and the microcirculation. Critical Care Clin. 2004;20(2):213-223. doi:10.10 16/j.ccc.2003.12.003

2. Sparks HV. Learning the regulation of peripheral blood flow. Am J Physiol. 1999;277(6 Pt 2):S164-173.

3. Ince C. Hemodynamic coherence and the rationale for monitoring the microcirculation. Crit Care. 2015;19(Suppl S3):S8. doi:10.1186/cc14726

4. Weil MH, Shubin H. Proposed reclassification of shock states with special reference to distributive defects. Adv Exp Med Biol. 1971;23:13-23.

5. Kanoore Edul VS, Ince C, Dubin A. What is microcirculatory shock? Curr Opin Crit Care. 2015;21(3):245-252. doi:10.1097/MCC.0000 000000000196

6. Ince C, Boerma EC, Cecconi M, et al. Second consensus on the assessment of sublingual microcirculation in critically ill patients: results from a task force of the European Society of Intensive Care Medicine. Intensive Care Med. 2018;44(3):281-299.

7. Groner W, Winkelman JW, Harris AG, et al. Orthogonal polarization spectral imaging: a new method for study of the microcirculation. Nat Med. 1999;5(10):1209-1212.

8. Pahernik S, Harris AG, Schmitt-Sody M, et al. Orthogonal polarisation spectral imaging as a new tool for the assessment of antivascular tumour treatment in vivo: a validation study. Br J Cancer. 2002;86 (10):1622-1627.

9. Harris AG, Sinitsina I, Messmer K. Validation of OPS imaging for microvascular measurements during isovolumic hemodilution and low hematocrits. Am J Physiol Heart Circ Physiol. 2002;282(4): H1502-H1509.

10. Goedhart PT, Khalilzada M, Bezemer R, Merza J, Ince C. Sidestream Dark Field (SDF) imaging: a novel stroboscopic LED ring-based imaging modality for clinical assessment of the microcirculation. Opt Express. 2007;15(23):15101-15114. doi:10. 1364/OE.15.015101

11. Aykut G, Veenstra G, Scorcella C, Ince C, Boerma C. Cytocam-IDF (incident dark field illumination) imaging for bedside monitoring of the microcirculation. Intensive Care Med Exp. 2015;3(1):40. doi:10.1186/s40635-015-0040-7

12. Hutchings S, Watts S, Kirkman E. The Cytocam video microscope. A new method for visualising the microcirculation using Incident Dark Field technology. Clin Hemorheol Microcirc. 2016;62 (3):261-271. doi:10.3233/CH-152013

13. Gilbert-Kawai E, Coppel J, Bountziouka V, et al. A comparison of the quality of image acquisition between the incident dark field and sidestream dark field video-microscopes. BMC Medical Imaging. 2016;16(1):10. doi:10.1186/s12880-015-0078-8

14. Coppel J, Bountziouka V, Martin D, Gilbert-Kawai E. A comparison of the quality of image acquisition between two different sidestream dark field video-microscopes. J Clin Monit Comput. 2020. doi:10.1007/s10877-020-00514-x

15. Massey MJ, Larochelle E, Najarro G, et al. The microcirculation image quality score: development and preliminary evaluation of a proposed approach to grading quality of image acquisition for bedside videomicroscopy. J Crit Care. 2013;28(6):913-917. doi:10.1016/j.jcrc.2013.06.015

16. Massey MJ, Hou PC, Filbin M, et al. Microcirculatory perfusion disturbances in septic shock: results from the ProCESS trial. Crit Care. 2018;22(1):308. doi:10.1186/s13054-018-2240-5

17. De Backer D, Creteur J, Preiser J-C, Dubois M-J, Vincent J-L. Microvascular blood flow is altered in patients with sepsis. $\mathrm{Am}$ $J$ Respir Crit Care Med. 2002;166(1):98-104. doi:10.1164/ rccm.200109-016OC

18. Boerma EC, Mathura KR, van der Voort PH, Spronk PE, Ince C. Quantifying bedside-derived imaging of microcirculatory abnormalities in septic patients: a prospective validation study. Crit Care. 2005;9(6):R601-R606. doi:10.1186/cc3809 
19. Pozo MO, Kanoore Edul VS, Ince C, Dubin A. Comparison of different methods for the calculation of the microvascular flow index. Crit Care Res Pract. 2012;2012:102483.

20. Trzeciak S, Dellinger RP, Parrillo JE, et al. Early microcirculatory perfusion derangements in patients with severe sepsis and septic shock: relationship to hemodynamics, oxygen transport, and survival. Ann Emerg Med. 2007;49(1):88-98. doi:10.1016/j. annemergmed.2006.08.021

21. Edul VS, Enrico C, Laviolle B, Vazquez AR, Ince C, Dubin A. Quantitative assessment of the microcirculation in healthy volunteers and in patients with septic shock. Crit Care Med. 2012;40 (5):1443-1448. doi:10.1097/CCM.0b013e31823dae59

22. De Backer D, Hollenberg S, Boerma C, et al. How to evaluate the microcirculation: report of a round table conference. Crit Care. 2007;11(5):R101. doi:10.1186/cc6118

23. Dobbe JG, Streekstra GJ, Atasever B, van Zijderveld R, Ince C. Measurement of functional microcirculatory geometry and velocity distributions using automated image analysis. Med Biol Eng Comput. 2008;46(7):659-670. doi:10.1007/s11517-008-0349-4

24. Hilty MP, Guerci P, Ince Y, Toraman F, Ince C. MicroTools enables automated quantification of capillary density and red blood cell velocity in handheld vital microscopy. Commun Biol. 2019;2 (1):217. doi:10.1038/s42003-019-0473-8

25. Bland JM, Altman DG. Statistical methods for assessing agreement between two methods of clinical measurement. Lancet. 1986;327 (8476):307-310. doi:10.1016/S0140-6736(86)90837-8

26. Dubin A, Pozo MO, Ferrara G, et al. Systemic and microcirculatory responses to progressive hemorrhage. Intensive Care Medicine. 2009;35(3):556-564. doi:10.1007/s00134-008-1385-0

27. Verdant CL, De Backer D, Bruhn A, et al. Evaluation of sublingual and gut mucosal microcirculation in sepsis: a quantitative analysis. Crit Care Med. 2009;37(11):2875-2881. doi:10.1097/CCM.0b01 $3 \mathrm{e} 3181 \mathrm{~b} 029 \mathrm{c} 1$

28. Kanoore Edul VS, Ince C, Estenssoro E, et al. The Effects of Arterial Hypertension and Age on the Sublingual Microcirculation of Healthy Volunteers and Outpatients with Cardiovascular Risk Factors. Microcirculation. 2015;22(6):485-492. doi:10.1111/micc.12219

29. Arnold RC, Parrillo JE, Dellinger R, et al. Point-of-care assessment of microvascular blood flow in critically ill patients. Intensive Care Medicine. 2009;35(10):1761-1766. doi:10.1007/s00134-009-1517-1

30. Sardinha J, MacKinnon S, Lehmann C. Rapid clinical assessment of the sublingual microcirculation - Visual scoring using microVAS in comparison to standard semi-automated analysis. Clin Hemorheol Microcirc. 2019;72(3):229-238. doi:10.3233/CH-180427

31. Tanaka S, Harrois A, Nicolaï C, et al. Qualitative real-time analysis by nurses of sublingual microcirculation in intensive care unit: the MICRONURSE study. Crit Care. 2015;19(1):388. doi:10.1186/ s13054-015-1106-3

32. Lima A, López A, van Genderen ME, et al. Interrater Reliability and Diagnostic Performance of Subjective Evaluation of Sublingual Microcirculation Images by Physicians and Nurses: A Multicenter Observational Study. Shock. 2015;44(3):239-244. doi:10.1097/ SHK.0000000000000401

33. Hutchings SD, Watchorn J, Trovato F, et al. Microcirculatory, Endothelial and Inflammatory Responses in Critically Ill Patients with COVID-19 are Distinct from those Seen in Septic Shock: A Case Control Study. Shock. 2020; Publish Ahead of Print. doi:10.1097/SHK.0000000000001672

34. Dubin A, Pozo MO, Casabella CA, et al. Increasing arterial blood pressure with norepinephrine does not improve microcirculatory blood flow: a prospective study. Crit Care. 2009;13(3):R92. doi:10.1186/cc7922

35. Boerma EC, van der Voort PHJ, Ince C. Sublingual microcirculatory flow is impaired by the vasopressin-analogue terlipressin in a patient with catecholamine-resistant septic shock. Acta Anaesthesiol Scand. 2005;49(9):1387-1390. doi:10.1111/j.1399-6576.2005.00752.x
36. Edul VS, Ince C, Vazquez AR, et al. Similar Microcirculatory Alterations in Patients with Normodynamic and Hyperdynamic Septic Shock. Ann Am Thorac Soc. 2016;13(2):240-247.

37. Ferrara G, Kanoore Edul VS, Martins E, et al. Intestinal and sublingual microcirculation are more severely compromised in hemodilution than in hemorrhage. $J$ Appl Physiol. 2016;120(10):1132-1140. doi:10.1152/japplphysiol.00007.2016

38. De Backer D, Orbegozo Cortes D, Donadello K, Vincent J-L. Pathophysiology of microcirculatory dysfunction and the pathogenesis of septic shock. Virulence. 2014;5(1):73-79. doi:10.4161/viru.26482

39. Lam C, Tyml K, Martin C, Sibbald W. Microvascular perfusion is impaired in a rat model of normotensive sepsis.. J Clin Invest. 1994;94(5):2077-2083. doi:10.1172/JCI117562

40. Ellis CG, Bateman RM, Sharpe MD, Sibbald WJ, Gill R. Effect of a maldistribution of microvascular blood flow on capillary $\mathrm{O} 2$ extraction in sepsis. Am J Physiol Heart Circ Physiol. 2002;282(1): H156-H164. doi:10.1152/ajpheart.2002.282.1.H156

41. Dubin A, Edul VSK, Pozo MO, et al. Persistent villi hypoperfusion explains intramucosal acidosis in sheep endotoxemia. Crit Care Med. 2008;36(2):535-542. doi:10.1097/01.CCM.0000300083.74726.43

42. Ince C, Sinaasappel M. Microcirculatory oxygenation and shunting in sepsis and shock. Crit Care Med. 1999;27(7):1369-1377. doi:10. 1097/00003246-199907000-00031

43. Hernandez G, Boerma EC, Dubin A, et al. Severe abnormalities in microvascular perfused vessel density are associated to organ dysfunctions and mortality and can be predicted by hyperlactatemia and norepinephrine requirements in septic shock patients. J Crit Care. 2013;28(4):538.e9-14. doi:10.1016/j.jcrc.2012.11.022

44. Sakr Y, Dubois M-J, De Backer D, Creteur J, Vincent J-L. Persistent microcirculatory alterations are associated with organ failure and death in patients with septic shock. Crit Care Med. 2004;32 (9):1825-1831. doi:10.1097/01.CCM.0000138558.16257.3F

45. De Backer D, Donadello K, Sakr Y, et al. Microcirculatory alterations in patients with severe sepsis: impact of time of assessment and relationship with outcome. Crit Care Med. 2013;41(3):791-799. doi:10.1097/CCM.0b013e3182742e 8b

46. Georger J-F, Hamzaoui O, Chaari A, Maizel J, Richard C, Teboul J-L. Restoring arterial pressure with norepinephrine improves muscle tissue oxygenation assessed by near-infrared spectroscopy in severely hypotensive septic patients. Intensive Care Medicine. 2010;36(11):1882-1889. doi:10.1007/s00134-010-2013-3

47. Gutierrez G. The rate of oxygen release and its effect on capillary $\mathrm{O} 2$ tension: a mathematical analysis. Respir Physiol. 1986;63(1):79-96. doi:10.1016/0034-5687(86)90032-0

48. Edul VS, Ferrara G, Pozo MO, et al. Failure of nitroglycerin (glyceryl trinitrate) to improve villi hypoperfusion in endotoxaemic shock in sheep. Crit Care Resusc. 2011;13(4):252-261.

49. Nakajima Y, Baudry N, Duranteau J, Vicaut E. Microcirculation in intestinal villi: a comparison between hemorrhagic and endotoxin shock. Am J Respir Crit Care Med. 2001;164(8):1526-1530. doi:10.1164/ajrccm.164.8.2009065

50. Edul VSK, Ince C, Navarro N, et al. Dissociation between sublingual and gut microcirculation in the response to a fluid challenge in postoperative patients with abdominal sepsis. Ann Intensive Care. 2014;4 (1):39. doi:10.1186/s13613-014-0039-3

51. Koning NJ, Simon LE, Asfar P, Baufreton C, Boer C. Systemic microvascular shunting through hyperdynamic capillaries after acute physiological disturbances following cardiopulmonary bypass. Am $J$ Physiol Heart Circ Physiol. 2014;307(7):H967-H975. doi:10.1152/ajpheart.00397.2014

52. Gonzalez Ballerga E, Pozo MO, Rubatto Birri PN, et al. Sublingual microcirculatory alterations in cirrhotic patients. Microcirculation. 2018;25(4):e12448. doi:10.1111/micc. 12448

53. Puleo F, Arvanitakis M, Van Gossum A, Preiser J-C. Gut failure in the ICU. Semin Respir Crit Care Med. 2011;32(5):626-638. doi:10.1055/s-0031-1287871 
54. van Genderen ME, Klijn E, Lima A, et al. Microvascular perfusion as a target for fluid resuscitation in experimental circulatory shock. Crit Care Med. 2014;42(2):e96-e105. doi:10.1097/CCM.0b013e3182a63fbf

55. Boerma EC, van der Voort PHJ, Spronk PE, Ince C. Relationship between sublingual and intestinal microcirculatory perfusion in patients with abdominal sepsis. Crit Care Med. 2007;35 (4):1055-1060. doi:10.1097/01.CCM.0000259527.89927.F9

56. Ferrara G, Kanoore Edul VS, Caminos Eguillor JF, et al. Effects of fluid and norepinephrine resuscitation in a sheep model of endotoxin shock and acute kidney injury. J Appl Physiol. 2019;127(3):788-797. doi:10.1152/japplphysiol.00172.2019

57. Eguillor JFC, Ferrara G, Edul VSK, et al. Effects of Systemic Hypothermia on Microcirculation in Conditions of Hemodynamic Stability and in Hemorrhagic Shock. Shock. 2020;Publish Ahead of Print. doi:10.1097/SHK.0000000000001616

58. Ince C. The rationale for microcirculatory guided fluid therapy. Curr Opin Crit Care. 2014;20(3):301-308. doi:10.1097/MCC.0000000000000091

59. Villela NR, Vázques BY, Intaglietta M. Microcirculatory effects of intravenous fluids in critical illness: plasma expansion beyond crystalloids and colloids. Curr Opin Anaesthesiol. 2009;22(2):163-167. doi:10.1097/ACO.0b013e328328d304

60. Morisaki H, Bloos F, Keys J, Martin C, Neal A, Sibbald WJ. Compared with crystalloid, colloid therapy slows progression of extrapulmonary tissue injury in septic sheep. J Appl Physiol. 1994;77(3):1507-1518.

61. Hoffmann JN, Vollmar B, Laschke MW, Inthorn D, Schildberg FW, Menger MD. Hydroxyethyl starch $(130 \mathrm{kD})$, but not crystalloid volume support, improves microcirculation during normotensive endotoxemia. Anesthesiology. 2002;97(2):460-470.

62. Dubin A, Pozo MO, Casabella CA, et al. Comparison of $6 \%$ hydroxyethyl starch 130/0.4 and saline solution for resuscitation of the microcirculation during the early goal-directed therapy of septic patients. J Crit Care. 2010;25(4):659.e1-e8.

63. Myburgh JA, Finfer S, Bellomo R, et al. Hydroxyethyl starch or saline for fluid resuscitation in intensive care. $N$ Engl $\mathrm{J} \mathrm{Med}$. 2012;367(20):1901-1911.

64. Ospina-Tascon G, Neves AP, Occhipinti G, et al. Effects of fluids on microvascular perfusion in patients with severe sepsis. Intensive Care Med. 2010;36(6):949-955.

65. Pottecher J, Deruddre S, Teboul JL, et al. Both passive leg raising and intravascular volume expansion improve sublingual microcirculatory perfusion in severe sepsis and septic shock patients. Intensive Care Med. 2010;36(11):1867-1874.

66. Pranskunas A, Koopmans M, Koetsier PM, Pilvinis V, Boerma EC. Microcirculatory blood flow as a tool to select ICU patients eligible for fluid therapy. Intensive Care Med. 2013;39(4):612-619.

67. Jhanji S, Stirling S, Patel N, Hinds CJ, Pearse RM. The effect of increasing doses of norepinephrine on tissue oxygenation and microvascular flow in patients with septic shock. Crit Care Med. 2009;37 (6):1961-1966
68. Fiorese Coimbra KT, de Freitas FGR, Bafi AT, et al. Effect of Increasing Blood Pressure With Noradrenaline on the Microcirculation of Patients With Septic Shock and Previous Arterial Hypertension. Crit Care Med. 2019;47(8):1033-1040.

69. De Backer D, Creteur J, Dubois MJ, et al. The effects of dobutamine on microcirculatory alterations in patients with septic shock are independent of its systemic effects. Crit Care Med. 2006;34 (2):403-408

70. Enrico C, Kanoore Edul VS, Vazquez AR, et al. Systemic and microcirculatory effects of dobutamine in patients with septic shock. J Crit Care. 2012;27(6):630-638.

71. Hernandez G, Bruhn A, Luengo C, et al. Effects of dobutamine on systemic, regional and microcirculatory perfusion parameters in septic shock: a randomized, placebo-controlled, double-blind, crossover study. Intensive Care Med. 2013;39(8):1435-1443.

72. Ospina-Tascón GA, Umaña M, Bermúdez WF, et al. Can venous-toarterial carbon dioxide differences reflect microcirculatory alterations in patients with septic shock? Intensive Care Med. 2016;42 (2):211-221.

73. De Backer D. Is microcirculatory assessment ready for regular use in clinical practice? Curr Opin Crit Care. 2019;25(3):280-284.

74. Diaztagle Fernández JJ, Rodríguez Murcia JC, Sprockel Díaz JJ. Venous-to-arterial carbon dioxide difference in the resuscitation of patients with severe sepsis and septic shock: A systematic review. Med Intensiva. 2017;41(7):401-410.

75. Muller G, Mercier E, Vignon $P$, et al. Prognostic significance of central venous-to-arterial carbon dioxide difference during the first 24 hours of septic shock in patients with and without impaired cardiac function. Br J Anaesth. 2017;119(2):239-248.

76. Dubin A, Pozo MO, Kanoore Edul VS, Risso Vazquez A, Enrico C. Poor agreement in the calculation of venoarterial $\mathrm{PCO}_{2}$ to arteriovenous $\mathrm{O}_{2}$ content difference ratio using central and mixed venous blood samples in septic patients. J Crit Care. 2018;48:445-450.

77. Hachamovitch R, Brown HV, Rubin SA. Respiratory and circulatory analysis of $\mathrm{CO}_{2}$ output during exercise in chronic heart failure. Circulation. 1991;84(2):605-612.

78. Dubin A, Ferrara G, Kanoore Edul VS, et al. Venoarterial $\mathrm{PCO}_{2}$-toarteriovenous oxygen content difference ratio is a poor surrogate for anaerobic metabolism in hemodilution: an experimental study. Ann Intensive Care. 2017;7(1):65.

79. Creteur J, De Backer D, Sakr Y, Koch M, Vincent JL. Sublingual capnometry tracks microcirculatory changes in septic patients. Intensive Care Med. 2006;32(4):516-523.
Vascular Health and Risk Management

\section{Publish your work in this journal}

Vascular Health and Risk Management is an international, peerreviewed journal of therapeutics and risk management, focusing on concise rapid reporting of clinical studies on the processes involved in the maintenance of vascular health; the monitoring, prevention and treatment of vascular disease and its sequelae; and the involvement of metabolic disorders, particularly diabetes. This journal is indexed on PubMed Central and MedLine. The manuscript management system is completely online and includes a very quick and fair peerreview system, which is all easy to use. Visit http://www.dovepress. com/testimonials.php to read real quotes from published authors. 